\title{
Association of Serum C-reactive Protein Levels with Gamma Glutamyl Transferase and Cardiometabolic Risk Factors in Middle Aged People
}

\author{
Kholoud S. Ramadan \\ Department of Biochemistry, Faculty of Science, \\ Ain Shams University, Cairo Egypt
}

\begin{abstract}
C-reactive protein (CRP) is an inflammatory marker shown to predict future cardiovascular morbidity and mortality. The aim of the present study was to investigate the association of serum CRP level as a marker of chronic inflammation with gamma glutamyl transferase (GGT) as early marker of oxidative stress and their association with cardiometabolic risk factors among a diverse community sample of mid-life people, also to examine whether these relationships might vary by age, sex and body mass index. The investigation was based on data derived from 100 apparently healthy volunteers (male 40, female 60) aged 20-50 years, had a BMI between 24.2 and $37.7 \mathrm{~kg} / \mathrm{m}^{2}$. Fasting serum CRP, GGT, uric acid and cardiovascular risk factors were measured and assessed in relation to CRP. Significant gender differences exist in the population distribution of CRP and GGT. In addition, higher BMI was significantly associated with higher CRP and uric acid. There was linear trend for increased prevalence of cardiovascular risk factors across CRP categories representing medium $(1-<3 \mathrm{mg} / \mathrm{L})$ and high $(3-10 \mathrm{mg} / \mathrm{L})$. After adjustment for sex, age and body mass index, serum concentration of CRP was positively associated with serum concentration of GGT and Uric acid $(P<0.05)$. Body mass index and systosolic blood pressure had the strongest association with CRP. The prevalence of metabolic syndrome (MS) progressively increased with elevated CRP levels. In conclusion, these data suggest that CRP is associated with two markers of oxidative stress, GGT and UA and elevation of both CRP and GGT may be worsening the atherogenic state. Furthermore, elevated CRP levels were associated with adverse lipid profiles and metabolic syndrome.
\end{abstract}

Key Words: Metabolic syndrome, cardiovascular diseases, C-reactive protein, BMI.

\section{INTRODUCTION}

C-reactive protein (CRP) is a cited marker of inflammatory status, shown to predict cardiovascular morbidity and mortality ${ }^{(\mathbf{1})}$. The CRP level is, also correlated with cardiovascular disease (CVD) risk factors in healthy men and women ${ }^{(2)}$.
Low-grade inflammation has, also been linked to the development of metabolic disorders regarding diabetes, hypertension and $\mathrm{MS}^{(3)}$. Furthermore, slightly elevated gamma glutamyl transferase (GGT) that is almost within the normal range is associated with all cause mortality ${ }^{(4)}$, and has emerged as an independent 
predictor of CVD, which is increasingly viewed as an inflammatory disease ${ }^{(5)}$. These associations can be partly explained by the known correlation of GGT with cardiovascular risk factors such as obesity $^{(\mathbf{6})}$, dyslipidemia ${ }^{(7)}$ and $\mathrm{MS}^{(\mathbf{8})}$.

Serum GGT is, also an independent marker of oxidative stress ${ }^{(9)}$ and increased GGT reflects increased oxidative stress ${ }^{(10)}$. Elevated GGT could, also reflect subclinical inflammation and several studies showed that serum GGT concentration predicted concentration of inflammation and oxidative stress markers, such as uric acid, $\mathrm{CRP}^{(\mathbf{1 1})}$.

Therefore, the present study was conducted to evaluate the association of elevated serum CRP with serum GGT and their relation to the atherogenic abnormalities. In addition, the association of CRP with the metabolic syndrome components and CVD in middle-aged Egyptian adults will be examined.

\section{MATERIALS \& METHODS}

The present study was based on data derived from 100 apparently healthy volunteers participating in Ain Shams University Hospitals: 40 men and 60 women, classified as either age 20-30 years, $\mathrm{n}=60$, mean $\pm \mathrm{SD}, 23.8$ \pm 2.2 years and $31-50$ years, $n=40$, mean $\pm \mathrm{SD}, 39.43 \pm 5.4$ years or CRP categories (12); medium CRP 1-<3 $\mathrm{mg} / \mathrm{L}, \mathrm{n}=45,2.16 \pm 1.6 \mathrm{mg} / \mathrm{L}$ and high CRP 3-10 mg/L, $\mathrm{n}=55,4.09 \pm$ $1.9 \mathrm{mg} / \mathrm{L}$ and further according to body mass index (BMI) (calculated as weight / height in $\mathrm{m}^{2}$ ): normal weight $\left(18.5-24.9 \mathrm{Kg} / \mathrm{m}^{2}, \mathrm{n}=10\right)$, overweight $\left(25-29.9 \mathrm{Kg} / \mathrm{m}^{2}, \mathrm{n}=65\right)$, or obese $(\geq 30$
$\left.\mathrm{Kg} / \mathrm{m}^{2}, \mathrm{n}=25\right)^{(\mathbf{1 3 )}}$. Waist circumference was obtained at the mid-point between the lowest rib and the iliac crest to the nearest $0.1 \mathrm{~cm}$, after inhalation and exhalation. Blood pressure was measured using an electronic blood pressure monitor on the right arm of the participant in a comfortable sitting position after at least $5 \mathrm{~min}$ rest

Subjects were premenopausal, were not currently pregnant, and were not under medication that effected weight or body composition. Other exclusions included a reported history of atherosclerotic cardiovascular disease, subjects with diagnosed metabolic abnormalities and who were taking medications known to affect CRP levels. Data of participants having circulating CRP levels $>10$ $\mathrm{mg} / \mathrm{L}$ (given extreme CRP values are usually not associated with cardiometabolic disorders) were not included in the study. All volunteers were informed about the research design and gave their written informed consent to participate in the study, which was approved by the ethical committee.

In the present study, metabolic syndrome (MS) was defined according to International Diabetes Federation (IDF) definition (14). Subjects were considered to have the MS if they met at least three of the following: high waist circumference $(\geq 80 \mathrm{~cm})$, raised blood pressure $(\geq 130 / 85 \mathrm{~mm} \mathrm{Hg})$, reduced HDL cholesterol $(<50 \mathrm{mg} / \mathrm{dl}), \quad$ raised triglycerides $(\geq 150 \mathrm{mg} / \mathrm{dl})$, and raised fasting plasma glucose $(\geq 100 \mathrm{mg} / \mathrm{dl})$ or previously diagnosed type 2 diabetes.

Ten $\mathrm{ml}$ fasting venous blood samples were taken. Two $\mathrm{ml}$ of the 
sample were added to sodium fluoride containing tube, then centrifuged at $3000 \mathrm{rpm}$ for 10 minutes at $40 \mathrm{C}$ and the separated plasma was used for blood glucose analysis. Another two $\mathrm{ml}$ of the sample were added to EDTA containing tube for measurement of blood HbA1c. Serum was obtained from the remaining blood by centrifugation $\&$ stored in aliquots at $80{ }^{\circ} \mathrm{C}$ until the time of assay of lipids and other analyses.

Glucose $^{(15)}$, total cholesterol (TC) level $^{(\mathbf{1 6})}$, triacylglycerol (TAG) level ${ }^{(17)}$, high-density lipoprotein cholesterol (HDL-C) level ${ }^{(18)}$ and uric acid (UA) level ${ }^{(19)}$ were measured using enzymatic methods. Lowdensity lipoprotein cholesterol (LDLC) was calculated by the Friedwald formula ${ }^{(20)}$. Glycosylated hemoglobin (HbA1c) was determined in whole blood using chromatographicSpectrophotometric methods ${ }^{(21)}$.

Enzyme activity for gamma glutamyl transferase (GGT) was measured using commercial reagent kit according to ${ }^{(22)}$. C-reactive protein (CRP) level was measured by (BioCheck high sensitivity CRP ELISA kit; Foster City). All samples were examined in duplicate, and the mean values of individual samples were used for statistical analysis.

\section{Statistical Analysis:}

Values were analyzed, as means \pm SD. Differences between groups were determined with student's t-test for independent samples and by oneway analysis of variance (ANOVA). The analyses were carried out using SPSS 11.0 for Windows statistical software (Chicago, IL, USA). Tests were considered statistically significant at $\mathrm{p}<0.05$. Correlation between variables was calculated by Pearson's correlation coefficient " $r$ ". Receiver operating characteristic curve (ROC curve) was constructed to evaluate the sensitivity and specificity of the markers, and to determine the best cut-off value for each marker.

\section{RESULTS}

The basic clinical characteristics of the male and female subjects are presented in table (1). The mean ages were $24.5 \pm 3.89$ years for males and $32.5 \pm 7.9$ years for females. Compared with men, women had higher systolic and diastolic blood pressure $(\mathrm{P}<0.001)$ and lower TC $(\mathrm{P}<0.05)$, while men had higher $\mathrm{TG}$ than women $(\mathrm{P}<0.001)$.

The median CRP values were 2.5 (interquartile range: $1-4$ ) $\mathrm{mg} / \mathrm{L}$ for males and four (interquartile range: 16) $\mathrm{mg} / \mathrm{L}$ for females. The median GGT values were 12 (interquartile range: 11.6-12.75) IU/L for males and 15 (interquartile range: 13.2-16) $\mathrm{IU} / \mathrm{L}$ for females. Serum UA concentration in male was significantly higher $(\mathrm{P}<0.01)$ than those in female, table (2). When the study subjects were further classified according to age and BMI, the highest concentrations of CRP, GGT and UA were found in aging and obese individuals, table (2).

Table (3) shows the associations between the two CRP categories and biological risk factors. The results demonstrate a linear trend for an increased prevalence of cardiovascular risk factors across the CRP categories.

Pearson's correlation analysis represented in table (4) revealed that, 
serum CRP was negatively correlated with SBP $(r=-0.37)$, BMI $(r=-0.33)$ and positively correlated with the biomarkers of oxidative stress, GGT $(\mathrm{r}=0.56)$ and $\mathrm{UA}(\mathrm{r}=0.33)$.

In separate analyses for men and women, the Pearson's correlation between CRP and BMI was significantly $(\mathrm{P}<0.05)$ stronger in women $(r=0.53)$ than in men $(r=0.41)$, table (5).

We next compared study subjects based on the number of metabolic syndrome criteria which were present. As subjects with five components of MS were rare (8), they were combined with subjects displaying four criteria. Fig (1) displays the distribution of CRP levels according to presence of total number of components of the MS. As shown, there was a strong linear increase in CRP levels as the number of components of the MS increased; mean CRP levels for those with $0,1,2,3,4$ characteristics of the MS were 1.83, 2.2, 3.46, 4.33, and 5.6 $\mathrm{mg} / \mathrm{L}$, respectively $(\mathrm{P}<0.001)$.

The receiver operating characteristic curve (ROC) analysis was used to evaluate the sensitivity, specificity and the best cut-off values of CRP and GGT for early prediction of cardiometabolic risk in aging subjects (31-50 years). It was indicated that the GGT was the best test with an area under the curve (AUC) equal 0.85 , the sensitivity was $87.5 \%$ and specificity was $79.17 \%$ at the cut-off value $=16 \mathrm{IU} / \mathrm{L}(95 \%$ confidence interval, $0.702-0.943)$ as shown in fig (2). The next most useful test was CRP with AUC equal 0.78, the sensitivity was $87.5 \%$ and specificity was $66.67 \%$ at the cut-off value $=3 \mathrm{mg} / \mathrm{L}$ (95\% confidence interval, $0.612-0.895$ ) as shown in fig (3).

Table (1): Clinical characteristics of the male and female subjects (Mean \pm SD)

\begin{tabular}{|l|c|c|c|}
\hline \multicolumn{1}{|c|}{ Characteristics } & $\begin{array}{c}\text { Total } \\
(\mathbf{n}=\mathbf{1 0 0})\end{array}$ & $\begin{array}{c}\text { Male } \\
(\mathbf{n = 4 0 )}\end{array}$ & $\begin{array}{c}\text { Female } \\
(\mathbf{n = 6 0})\end{array}$ \\
\hline Age $($ years $)$ & $29.3 \pm 7.6$ & $24.5 \pm 3.89$ & $32.5 \pm 7.9^{*}$ \\
\hline SBP $(\mathrm{mmHg})$ & $127.7 \pm 13.9$ & $120.4 \pm 4.6$ & $138 \pm 16.4^{*}$ \\
\hline DBP $(\mathrm{mmHg})$ & $81.8 \pm 10.7$ & $77.08 \pm 8.1$ & $89 \pm 10.3^{*}$ \\
\hline BMI $\left(\mathrm{Kg} / \mathrm{m}^{2}\right)$ & $28.5 \pm 4.5$ & $27.4 \pm 4.3$ & $30.25 \pm 4.5$ \\
\hline WC $(\mathrm{cm})$ & $84.7 \pm 14.03$ & $85.04 \pm 17.3$ & $84.2 \pm 7.14$ \\
\hline TC $(\mathrm{mg} / \mathrm{dl})$ & $138.6 \pm 22.6$ & $147.5 \pm 36$ & $125.3 \pm 26^{* *}$ \\
\hline LDL-c $(\mathrm{mg} / \mathrm{dl})$ & $93.6 \pm 35$ & $89.4 \pm 27.9$ & $99.8 \pm 62.3$ \\
\hline HDL-c (mg/dl) & $43.6 \pm 5.5$ & $43.4 \pm 4.3$ & $44 \pm 9.8$ \\
\hline TG $(\mathrm{mg} / \mathrm{dl})$ & $126.5 \pm 17$ & $159.08 \pm 2.03$ & $77.8 \pm 37.7^{*}$ \\
\hline Glucose $(\mathrm{mg} / \mathrm{dl})$ & $111.8 \pm 16.2$ & $113.7 \pm 6.8$ & $109.09 \pm 3.9$ \\
\hline HbA1c $(\%)$ & $7.25 \pm 1.5$ & $7.8 \pm 3.05$ & $6.4 \pm 3.3$ \\
\hline
\end{tabular}

$* \mathrm{P}<0.001,{ }^{* *} \mathrm{P}<0.05$ 
Table (2): CRP, GGT and UA concentrations according to gender, aging, and BMI $($ Mean $\pm \mathrm{SD})$

\begin{tabular}{|c|c|c|c|c|}
\hline Total & $\mathbf{N}$ & CRP $(\mathbf{m g} / \mathbf{L})$ & $\begin{array}{c}\text { GGT } \\
(\mathbf{I U} / \mathbf{L})\end{array}$ & $\begin{array}{c}\text { UA } \\
(\mathbf{m g} / \mathbf{d l})\end{array}$ \\
\hline Gender & & & & \\
Men & 40 & $2.75 \pm 1.98$ & $12.4 \pm 1.56$ & $5.7 \pm 0.8$ \\
Women & 60 & $4.04 \pm 2.2^{*}$ & $14.5 \pm 2.01^{*}$ & $4.9 \pm 0.64^{*}$ \\
\hline Aging & & & & \\
20-30 years & 60 & $2.41 \pm 1.86$ & $15.07 \pm 4.2$ & $5.04 \pm 0.6$ \\
31-50 years & 40 & $4.43 \pm 1.6^{*}$ & $18.41 \pm 2.1^{*}$ & $5.65 \pm 0.48^{*}$ \\
\hline BMI(Kg/m $\left.{ }^{2}\right)$ & & & & \\
Normal & 10 & $1.7 \pm 1.5$ & $15.9 \pm 3.5$ & $4.4 \pm 0.85$ \\
Overweight & 65 & $2.69 \pm 1.87$ & $16.7 \pm 3.9$ & $5.2 \pm 0.68 \dagger$ \\
Obese & 25 & $4.7 \pm 1.63 \dagger \dagger$ & $18 \pm 2.9$ & $5.5 \pm 0.39 \dagger$ \\
\hline
\end{tabular}

$* P<0.01$.

$\dagger P<0.05$, significantly different from normal BMI group.

$\dagger+P<0.001$; significantly different from normal and overweight BMI. groups

Table (3): Association between CRP categories, GGT and biological risk factors (Mean \pm SD)

\begin{tabular}{|c|c|c|}
\hline \multirow{2}{*}{ Variable } & \multicolumn{2}{|c|}{ CRP category } \\
\cline { 2 - 3 } & $\begin{array}{c}\text { Medium } \\
(\mathbf{n}=\mathbf{4 5})\end{array}$ & $\begin{array}{c}\text { High } \\
\mathbf{( n = 5 5 )}\end{array}$ \\
\hline GGT $(\mathrm{IU} / \mathrm{L})$ & $13.53 \pm 2.1$ & $18.75 \pm 3.4^{*}$ \\
\hline BMI $\left(\mathrm{Kg} / \mathrm{m}^{2}\right)$ & $25.9 \pm 1.2$ & $30.6 \pm 5.1^{*}$ \\
\hline WC $(\mathrm{cm})$ & $79.6 \pm 9.3$ & $88.8 \pm 15.9^{*}$ \\
\hline HDL-c $(\mathrm{mg} / \mathrm{dl})$ & $45.16 \pm 2.7$ & $43.2 \pm 6.9$ \\
\hline LDL-c $(\mathrm{mg} / \mathrm{dl})$ & $90.4 \pm 29$ & $91.6 \pm 40$ \\
\hline TC $(\mathrm{mg} / \mathrm{dl})$ & $138 \pm 28$ & $140.6 \pm 17$ \\
\hline SBP $(\mathrm{mmHg})$ & $120.5 \pm 5.3$ & $85.9 \pm 9.3^{*}$ \\
\hline DBP $(\mathrm{mmHg})$ & $76.9 \pm 10.4$ & $115.9 \pm 21$ \\
\hline Glucose $(\mathrm{mg} / \mathrm{dl})$ & $115.2 \pm 7.1$ & $6.56 \pm 1.8$ \\
\hline HbA1c $(\%)$ & $5.7 \pm 0.98$ & \\
\hline
\end{tabular}

$* \mathrm{P}<0.01, * * \mathrm{P}<0.05$ 
Table (4): Pearson correlation coefficient of CRP with Atherosclerotic risk factors and oxidative stress markers

\begin{tabular}{|l|c|c|c|c|c|c|c|c|c|}
\hline & CRP & GGT & UA & SBP & DBP & BMI & WC & HDL-c & TAG \\
\hline GGT & $0.56^{*}$ & & & & & & & & \\
\hline UA & $0.33^{*}$ & $0.5^{*}$ & & & & & & & \\
\hline SBP & $-0.37^{*}$ & 0.27 & 0.27 & & & & & & \\
\hline DBP & -0.11 & 0.3 & 0.15 & $0.66^{*}$ & & & & & \\
\hline BMI & $-0.33^{*}$ & 0.2 & 0.15 & $0.58^{*}$ & $0.31^{*}$ & & & & \\
\hline WC & -0.15 & -0.02 & 0.21 & 0.14 & 0.08 & $-0.7^{*}$ & & & \\
\hline HDL-c & -0.3 & -0.08 & -0.14 & 0.02 & -0.02 & 0.27 & 0.17 & & \\
\hline TAG & 0.28 & 0.2 & -0.21 & $-0.6^{*}$ & -0.43 & $-0.3 *$ & -0.05 & -0.06 & \\
\hline Glucose & 0.02 & -0.11 & 0.07 & -0.06 & -0.01 & -0.09 & 0.05 & 0.01 & 0.05 \\
\hline
\end{tabular}

$* P$-value: Correlation is significant at the 0.05 level.

Table (5): Pearson correlation coefficient of CRP with biological risk factors in male and female subjects

\begin{tabular}{|l|c|c|}
\hline & Men & Women \\
\hline Age & -0.29 & -0.47 \\
\hline BMI & $0.41^{*}$ & $0.53^{*}$ \\
\hline SBP & 0.23 & $0.6^{*}$ \\
\hline DBP & 0.26 & 0.1 \\
\hline TC & 0.05 & -0.02 \\
\hline HDL-c & -0.01 & 0.11 \\
\hline TAG & 0.33 & -0.69 \\
\hline Glucose & $-0.5^{*}$ & -0.34 \\
\hline
\end{tabular}

*P-value: Correlation is significant at the 0.05 level.

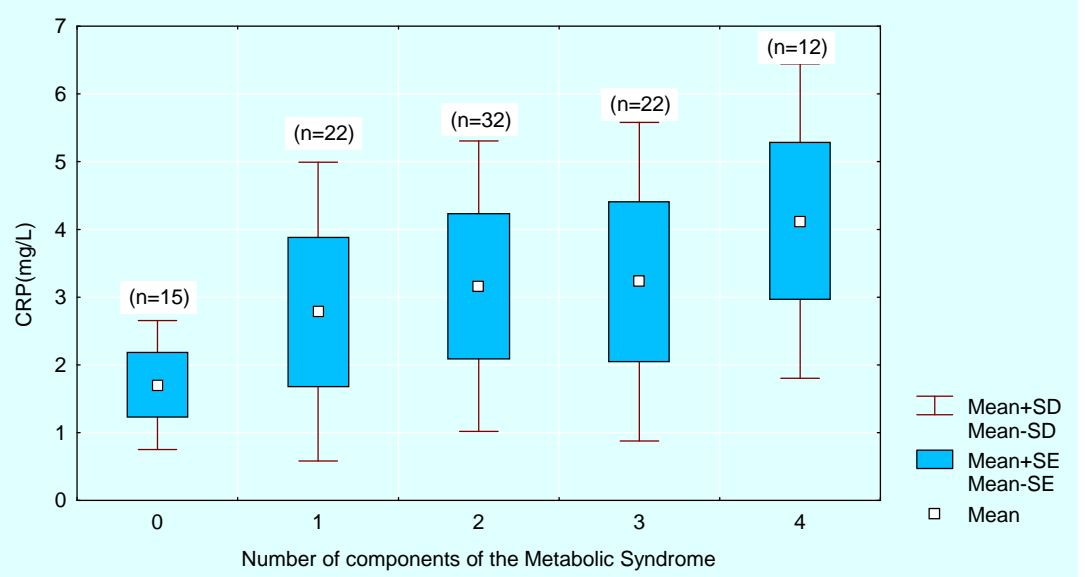

Fig. (1): Distribution of CRP levels according to the numbers of components of the metabolic syndrome. 


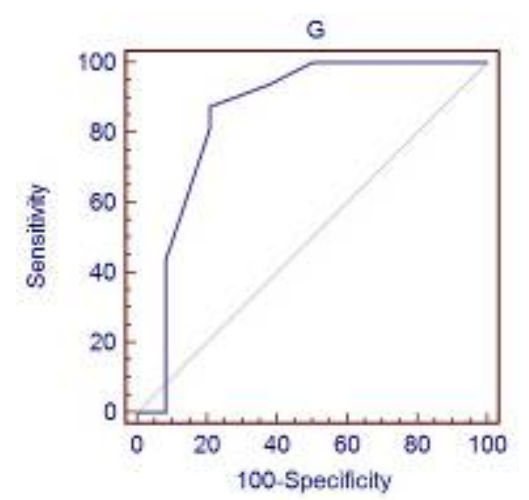

Fig. (2): ROC curve of GGT. Area under the curve equal 0.85 .

\section{DISCUSSION}

C-reactive protein (CRP) is the most extensively inflammatory risk marker and higher levels of it are associated with cardiac events in healthy men and women ${ }^{(23)}$. The present study aimed to evaluate the relationships between serum CRP levels with GGT as marker of oxidative stress and the cardiometabolic risk factors among healthy adult people.

Low grade systemic inflammation is common in aging people and may cause chronic disease, the present results add to previous studies by investigating an association between increasing level of CRP and other clinical markers of cardiovascular risk. Gaining more information about novel biomarkers in aging peoples is important because the accurate value of classic risk factors is decreased with advancing age ${ }^{(\mathbf{1 2})}$. Furthermore, the current findings demonstrated that CRP level varies by sex, age and

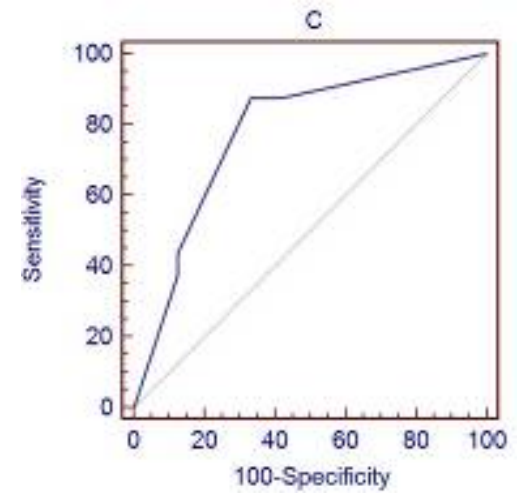

Fig. (3): ROC curve of CRP. Area under the curve equal 0.78 .

BMI. That result is, however, consistent with other studies on western samples that show higher CRP levels in females (24), whereas one cross-sectional study of Japanese males and females aged 30 years and over showing higher CRP in men ${ }^{(25)}$. The reason for these sex discrepancies is unclear but suggests that race and environmental factors should be considered in association with CRP. Of the total population, $50 \%$ of men and $41.6 \%$ of women had CRP levels less than $3 \mathrm{mg} / \mathrm{L}$, whereas only $50 \%$ of men and $58.3 \%$ of women had CRP levels above $3 \mathrm{mg} / \mathrm{L}$.

Recent studies have suggested a role for uric acid as a mediator of cardiovascular and metabolic syndrome $^{(\mathbf{2 6})}$. Elevated uric acid concentrations are, also associated with increased serum antioxidant capacity and reduced oxidative stress during acute physical exercise among healthy subjects ${ }^{(27)}$. Previous works reported that obesity increase GGT in an additive manner. GGT is 
responsible for the extracellular metabolism of glutathione, the main antioxidant in mammalian cells and GGT enzyme induction may be specifically associated with the generation of reactive oxygen species. Obviously, the links between serum uric acid, oxidative stress, and biomarkers of liver status, which associate with various biochemical and anthropometric features of the metabolic syndrome, also warrant future studies $^{(\mathbf{2 8})}$.

The current data further showed a linear trend for an increased prevalence of cardiovascular risk factors across CRP categories, which included a marker of diabetes risk, blood pressure and cholesterol. In addition, the current results recorded that high CRP that was defined as $>3 \mathrm{mg} / \mathrm{L}$ was associated with components of metabolic syndrome, and this was largely explained through the effects of central adiposity ${ }^{(\mathbf{1 2})}$.

There are several mechanisms underlying the association of GGT with MS. First, GGT has a central role in glutathione homeostasis by initiating the breakdown of extracellular glutathione. As glutathione, an antioxidant protects cells from toxins such as free radicals, increases in GGT may be a marker of oxidative stress and increased GGT reflects increased oxidative stress ${ }^{(\mathbf{1 0})}$. Increased oxidative stress, also, impaired insulin secretion by promoting $\beta$-cell dysfunction, and reduced insulin action by activation of multiple stress-serine/threonine kinase signaling cascades. The significant relationship that has been found between GGT and CRP is possibly due to their association with oxidative stress, which is a cardiovascular risk factor ${ }^{(29)}$.

Consistent with the previous studies $^{(30)}$; BMI is a mediator for the association between CRP and the MS. However, even though, BMI has a predominant influence on the CRP profile and the overall risk of MS, the present data showed that the increased CRP levels were highly associated with the individual features of MS. CRP also, has several direct effects at the level of the vessel wall and its measurement adds important prognostic information to clinical definitions of the MS is thus consistent with this that hypothesis.

In addition, to BMI, CRP was also found to be closely correlated with SBP in female subjects. The mechanisms underlying the association of CRP with BMI might be as follows; the adipose tissue is a source of cytokines such as tumor necrosis factor and interleukin-6, and these cytokines stimulate the production of acute-phase proteins such as CRP in the liver ${ }^{(31)}$.

ROC analyses showed the predictive power of GGT was larger than CRP in aging subjects. That result shows that GGT could be used as the predictive marker for future risk of cardiometabolic diseases.

In conclusion, these results suggest that GGT might be associated with increased CRP levels in males and females. Given that, GGT is easily measured and is extensively used. In addition, elevated CRP is highly associated with the metabolic syndrome. Further work is required to investigate the role of very highelevated CRP in cardiovascular risk diseases in elderly peoples and to 
clarify whether GGT is related to atherosclerotic disease after adjustment for cardiovascular risk factors.

\section{Acknowledgements:}

The author wish to thank Dr. Khaled Z. Elkarmouty, Assistant Professor at Department of Internal Medicine, Faculty of Medicine, Ain Shams University, for his kind help.

\section{REFERENCES}

1. Danesh J., Wheeler J. G., Hirschfield G. M., Eda S., Eiriksdottir G., Rumley A., Lowe G. D., Pepys M. B., and Gudnason V. (2004): C-reactive protein and other circulating markers of inflammation in the prediction of coronary heart disease. $N$ Engl $J$ Med., 350: 1387-97.

2. Wu D. M., Chu N. F., Shen M. H., and Chang J. B. (2003): Plasma C-reactive protein levels and their relationship to anthropometric and lipid characteristics among children. $J$ Clin Epidemiol. 56(1): 94-100.

3. Niskanen L., Laaksonen D. E., Nyyssonen K., et al. (2004): Inflammation, abdominal obesity, and smoking as predictors of hypertension. Hypertension. 44: 859-65.

4. Karison B. W., Wiklund O., Hallgren P., Sjolin M., Lindqvist $J$. and Herlitz $J$. (2000): Ten-year mortality amongst patients with a very small or unconfirmed acute myocardial infarction in relation to clinical history, metabolic screening and signs of myocardial ischemia. J Intern Med., 247: 449-56.

5. Lee M. Y., Koh S. B., Koh J. H., et al. (2008): Relationship between gammaglutamyltransferase and metabolic syndrome in a Korean population. Diabet Med, 25: 46975.

6. Lee D. H., Gross M. D., Jacobs Jr. Dr. (2004): Cardiovascular risk development in young adults study. Association of serum carotenoids and tocopherols with gamma-glutamyl transferase. Clin Chem., 50: 582-8.

7. Nilssen O., Forde O. H. and Brenn T. (1990): The Tromso study. Distribution and population determinants of gamma-glutamyltransferase. Am J Epidemiol. 132: 318-26.

8. Nakanishi N., Takatorige $T$. and Suzuki K. (2004): Daily life activity and risk of developing impaired fasting glucose or type 2 diabetes in middle-aged Japanese men. Diabetologia, 47: 1768-75.

9. Simão A. N, Dichi J. B, Barbosa D. S, Cecchini R., and Dichi I. (2008): Influence of uric acid and gamma-glutamyltransferase on total antioxidant capacity and oxidative stress in patients with metabolic syndrome. Nutrition, 24(7-8):675-81.

10. Blaha $M$. and Elasy T. A. (2006): Clinical use of the metabolic syndrome: why the confusion? Clin Diabetes. 24: 125-31.

11. Jo S. K., Lee W. Y, Rhee E. J., Won J. C. et al. (2009): Serum $\gamma$-glutamyl transferase activity predicts future development of 
metabolic syndrome defined by 2 different criteria. Clinica Chimica Acta.

12. Hamer M. and Chida Y. (2009): Associations of very high Creactive protein concentration with psychosocial and cardiovascular risk factors in an ageing population. Atherosclerosis.

13. Garrow J. S., Webster J. (1985): Quetele's Index (W/H2) as a measure of fatness." Internet Journal Obesity" 9.

14. Alberti K.G., Zimmet P., and Shaw J. (2005): The metabolic syndrome-a new worldwide definition. Saudi Medical Journal, 26:1781-1785.

15. Barham $D$. and Trinder $P$. (1972): An important color reagent for the determination of blood glucose by the oxidase system. Analyst; 97: 142-145.

16. Allain C.C., Poon L. S., Chan C. S., Richmond W., and Pu F. C. (1974): Enzymatic determination of total serum cholesterol. Clin. Chem. 20: 470 -475 .

17. McGowan M. W., Artiss J. D., Strandberrgh D. R., and Zak B. A. (1973): Peroxidase-coupled method for the colorimetric determination of serum triglycerides. Clin. Chem.; 29; $538-542$.

18. Finley P. R, Schifman R. B., Williams R. J., and Lichti D. A. (1978): Cholesterol in highdensity lipoprotein: use of $\mathrm{Mg} 2+/$ dextran sulphate in its enzymatic measurement. Clin. Chem., 24(6): $931-933$.
19. Fossati P, Prencipe L, and Berti G. (1980): Use of 3, 5-dichloro2-hydroxybenzenesulfonic acid/4aminophenazone chromogenic system in direct enzymic assay of uric acid in serum and urine. Clin Chem., 26(2):227-31.

20. Friedewald W. T., Levy R. I., and Fredrickson D. S. (1972): Estimation of the concentration of low-density lipoprotein cholesterol in plasma, without use of the preparative ultracentrifuge. Clin. Chem., 18 (6):499-502.

21. Bisse E., Abraham A., Stallings M., Perry R. E., and Abraham, E. C., (1986): High-performance liquid chromatographic separation and quantitation of glycosylated hemoglobin A2 as an alternate index of glycemic control. J. Chromatogr., 24, 374 (2):259-269.

22. Szasz G., Persijn, J.P. and Coll, E. (1974) Kinetic Method for quantitative determination of gammaglutamyl transpeptidase. Z. Klin. Chem. Klin. Biochem. 12, 228.

23. Albert C. M., Ma J., Rifai N., Stampfer M. J. and Ridker P. M. (2002): Prospective study of C-reactive protein, homocysteine, and plasma lipid levels lipid levels as predictors of sudden cardiac death. Circulation. 105: 2595-9.

24. Rogowski O., Zeltser D., Shapira I., Burke M., Zakut V., Mardi T., Ben-Assayag E., Serov J., Rozenblat M., and Berliner S. (2004): Gender differences in C-reactive protein concentrations in individuals with atherothrombotic risk factors and 
apparently healthy ones. Biomarkers. 9: 85-92

25. Yamada S., Gotoh T., Nakashima Y., Kayaba K., Ishikawa S., Nago N., et al. (2001): Distribution of serum Creactive protein and its association with atherosclerotic risk factors in a Japanese population: Jichi Medical School Cohort Study. Am J Epidemiol. 153: 1183-90.

26. Chien K. L., Chen M. F., Hsu H. C., Chang W. T., Su T. C., Lee Y. T., and Hu F. B. (2008): Plasma uric acid and the risk of type 2 diabetes in a Chinese community. Clin. Chem. 54: 310316.

27. Waring W. S., Convery A., Mishra V., Shenkin A., W ebb D. J., and Maxwell S. R. (2003): Uric acid reduces exerciseinduced oxidative stress in healthy adults. Clin Sci. 105: 425430.

28. Hanley A. J., Williams K., Festa 32.

\begin{abstract}
A., Wagenknecht L. E.,
\end{abstract}
D'Agostino Jr. R. B. and Haffner S. M. (2005): Liver markers and development of the metabolic syndrome: the insulin resistance atherosclerosis study. Diabetes. 54: 3140-3147.

29. Saijo Y., Utsugi M., Yoshioka E., Horikawa N., Sato T., Gong Y. and Kishi R. (2008): The relationship of gammaglutamyltransferase to C-reactive protein and arterial stiffness. Nutrition, Metabolism \& Cardiovascular Diseases. 18: 211-219.

30. Ye X., Yu Z., Li H., Franco O. H., Liu Y. and Lin X. (2007): Distribution of C-reactive protein and its association with metabolic syndrome in middle aged and older Chinese people. J Amer Coll Cardiol., 49:1798-805.

31. Bassuk S. S., Rifai N., and Ridker P. M. (2004): Highsensitivity C-reactive protein: clinical importance. Curr Probl Cardiol. 29: 439-93. 


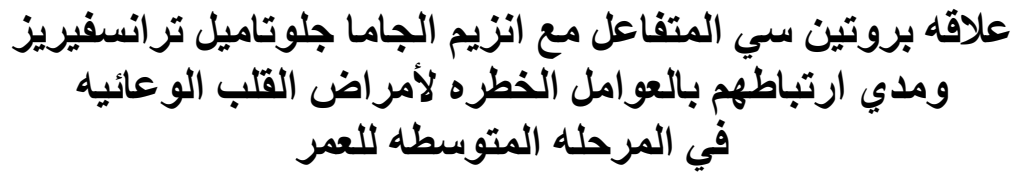

\author{
خلود صلاح الدين عبد العال رمضان \\ قسم الكيمياء الحيويه-كليه العلوم-جامعه عين شمس رسف
}

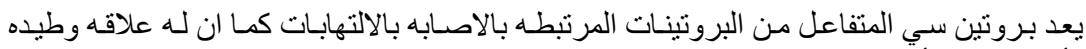

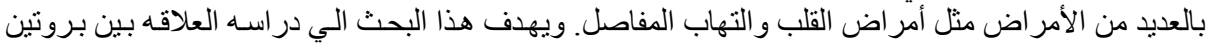

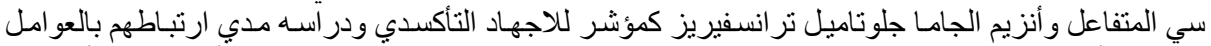

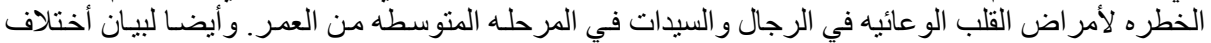

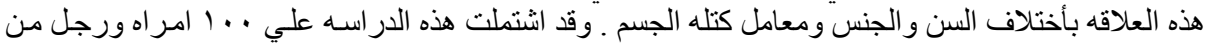

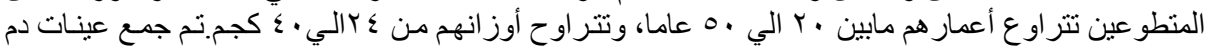

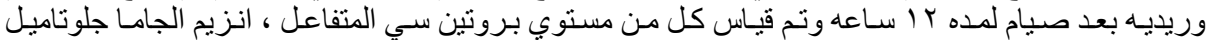

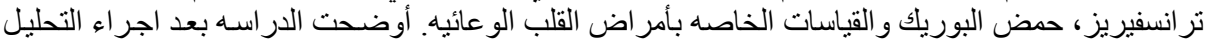

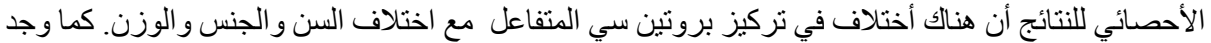

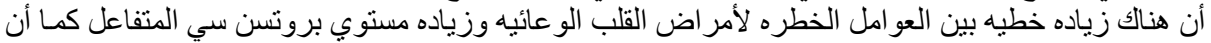

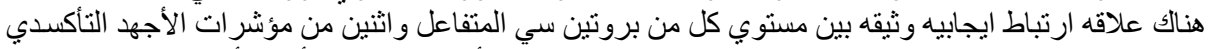

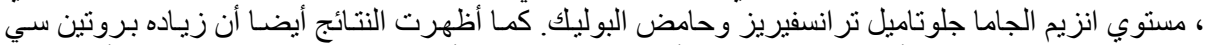

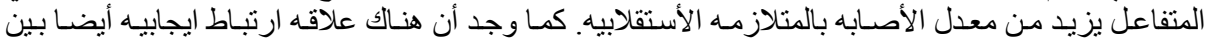

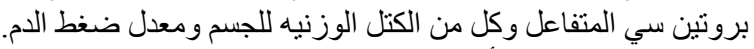

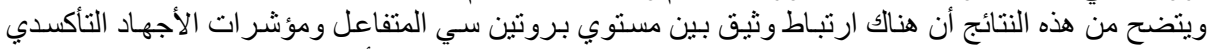

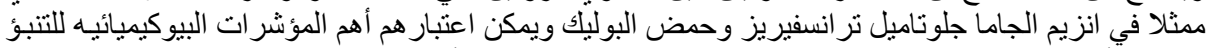

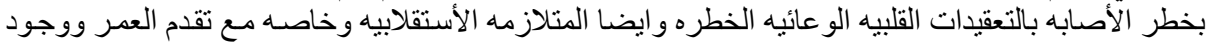
زياده في الوزن. 